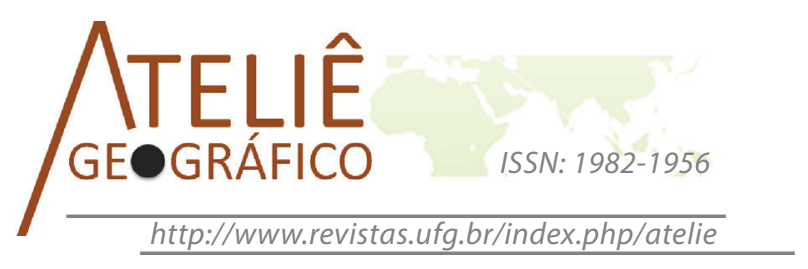

\title{
Minas que valorizam o patrimônio geomineiro para o turismo e educação: exemplos de Idrija (Eslovênia) e Passagem (Minas Gerais - Brasil)
}

\author{
Mines that value geomining heritage for tourism and \\ education: the examples of Idrija (Slovenia) and \\ Passagem (Minas Gerais - Brazil)
}

Mines qui valorisent le patrimoine géominière pour le tourisme et l'éducation: des exemples des mines d'Idrija (Slovénie) et de la mine du Passage (Brésil)

Úrsula Ruchkys

Universidade Federal de Minas Gerais (Brasil)

tularuchkys@yahoo.com.br

Luiz Eduardo Panisset Travassos

Pontifícia Universidade Católica de Minas Gerais (Brasil)

luizepanisset@gmail.com

Bojan Režun

Idrija Mercury Mine, Ltd. Information and Research Centre for Mercury

(Slovenia)

Vodja strokovne skupine - Geopark Idrija (Slovenia)

bojan.rezun@gmail.com

\begin{abstract}
Resumo
Em várias regiões que tem sua história ligada à extração mineral, minas exauridas são preparadas e abertas para visitação pública buscando valorizar o patrimônio geomineiro. Este é o caso das minas de Idrija (Eslovênia), e da mina da Passagem (Brasil). Com intuito comparativo o trabalho teve como principal objetivo analisar estas duas minas abertas para o turismo. Buscou-se compreender e descrever o contexto geológico e histórico das minas; analisou-se a proposta de visitação, divulgação e promoção científica e educativa; bem como a existência de programas voltados para públicos específicos. Trata-se de uma análise exploratória, qualitativa
\end{abstract}


e documental que incluiu visita de campo as duas minas. Os resultados indicam que embora as minas da Passagem e de Idrija sejam exemplos de reabilitação do patrimônio geomineiro, a exploração das potencialidades museológicas, turísticas, formativas e lúdicas é realizada de forma diferente o que interfere na qualidade da visitação e na valorização do patrimônio.

Palavras-chave: Patrimônio geomineiro; Brasil; Eslovênia; Passagem; Idrija

\begin{abstract}
In several regions in the world, which have their history linked to mining, exhausted mines are often prepared and open for public visitation in order to promote knowledge about the geomining heritage. This is the case of both the Idrija Mine (Slovenia) and the Passagem Mine (Brazil). Aiming at doing a comparative work, the main objective of this paper was to analyze these two mines that are open for tourism. The authors sought to understand and describe the geological and historical context of the mines, analyze the proposals for visitation, dissemination and scientific and educational promotion as well as the existence of programs for specific groups. This research is an exploratory, documentary and qualitative analysis that included field visits into these two mines. The results indicate that although the mines of Idrija and Passagem are examples of the rehabilitation of geomining heritage, the potential museological, tourist, educational and recreational use are different, a fact that interferes with the quality of visitation and appreciation of this heritage.
\end{abstract}

Keywords: Geomining heritage; Brazil; Slovenia; Passagem; Idrija

\begin{abstract}
Résumé
Dans plusieurs régions liées historiquement à l'extraction minérale, des mines épuisées sont aménagées et ouvertes au public dans le but de mettre en valeur le patrimoine des richesses du sous-sol. C'est le cas des mines d'Idrija (Slovénie), et de la mine du Passage (Brésil). L'objectif de ce travail est d'analyser et de comparer ces deux mines ouvertes au tourisme. Notre recherche nous amène à comprendre et à décrire leur contexte géologique et historique. Nous avons analysé les propositions de visites, de divulgation et de promotion scientifique et éducative, ainsi que l'existence de programmes tournés vers de publics spécifiques. Il s'agit d'une analyse exploratoire, qualitative et documentaire qui a inclus la visite du site des deux mines. Les résultats indiquent que bien que les mines du Passage et d'Idrija soient des exemples de réhabilitation du patrimoine des richesses du sous-sol, l'exploitation des potentialités muséologiques, touristiques, éducatives et ludiques est réalisée de façon différente ce qui interfère sur la qualité de visites et la valorisation du patrimoine.
\end{abstract}

Mots-clefs : Patrimoine des richesses du sous-sol ; Brésil ; Slovénie ; Passage ; Idrija

\title{
Introdução
}

A sociedade atual demanda um contínuo suprimento de recursos minerais e uma das preocupações mais importantes, além daquelas relativas ao desenvolvimento de técnicas para exploração que cause menor impacto ambiental, está associada à utilização destas áreas após o esgotamento do bem mineral. 
É possível dizer que toda atividade mineraria tem um patrimônio geológico e histórico-cultural a ela associado. Depois de encerradas as atividades de uma mina, é importantes que este espólio patrimonial esteja disponível ao público com infraestrutura adequada para visitação e fruição dos recursos geológicos, históricos e culturais associados ao desenvolvimento da mina, contribuindo desta forma, com a promoção do desenvolvimento daquela região mesmo depois de exaurido os recursos.

A utilização de minas para uso público ligado a visitação turística e a educação está associada aos conceitos de patrimônio geológico e mineiro. O patrimônio geológico é definido por Brilha (2005, p. 25) como sendo a ocorrência de um ou mais elementos da geodiversidade (afloramentos quer em resultado da ação de processos naturais quer devido à intervenção humana), bem como delimitados geograficamente e que apresente valor singular do ponto de vista científico, pedagógico, cultural, turístico ou outro.

Já o patrimônio mineiro é definido por Carcavilla et al. (2012) como o conjunto de trabalhos de mineração de interior e exterior, instalações, estruturas móveis e imóveis, documentos, objetos e elementos imateriais vinculados às atividades minerárias do passado e que apresenta valores históricos, culturais e sociais.

Desta forma, entende-se que o patrimônio mineiro se relaciona com o patrimônio geológico uma vez que a mineração se desenvolve associada a ocorrências minerais e de rochas, além de se relacionar com o patrimônio cultural (em especial o arqueológicoindustrial) e histórico. Por esse motivo, considera-se a mineração com sendo uma das indústrias tradicionais que mais deixa uma herança associada aos elementos das atividades extrativistas incluindo, além disto, "o legado histórico de raízes culturais" conforme salienta Valcarcel (1998).

Nos últimos anos é crescente, em vários países, a consciência social e a sensibilidade para a conservação e o uso da herança associada ao patrimônio geológico e mineiro e, consequentemente, existe um reconhecimento de que este patrimônio precisa ser disseminado por meio de museus, parques culturais, parques temáticos, geoparques, etc. Historicamente Riart (2000) salienta que as primeiras minas museus ou visitas subterrâneas abertas ao público surgiram em 1932 na mina de Interbrüll (Hinterbrühl, Áustria) e em 1934 com o museu da mina de Houllière, em Bexbach, na Alemanha. A partir daí outras várias passaram a ser abertas para visitação, como por exemplo, a mina museu de Chaterley, na Inglaterra (1979), o Creusot Montceau-les-Mines, na França (1973), a mina museu de Bois-du-Luc na Bélgica (1979), Langban, na Suécia (1983) e as minas de prata Kongsberg, na Noruega (1987). Assim, a conservação do patrimônio mineiro é uma realidade com vários outros exemplos que incluem, além daqueles citados por Riart (2000), a mina de Lousal (Portugal), a mina de sal Wieliczka (Polônia) e a bacia mineira de Nord-Pas-de-Calais em Lile (França).

Neste contexto, o artigo tem como objetivo apresentar a experiência de duas minas relevantes no cenário mundial: a mina de ouro de Passagem, localizada em Mariana, Minas Gerais, Brasil e a mina de mercúrio de Idrija, localizada na cidade de homônima, na Eslovênia (Figura 1). Ambas as minas foram exploradas economicamente e depois de encerradas as atividades de extração mineral foram recuperadas e requalificadas de forma 
a conservarem seus valores patrimoniais para utilização turística e educativa. Da mina da Passagem foram extraídas, oficialmente, 35 toneladas de ouro durante 284 anos de exploração. Da mina de Idrija, segunda maior jazida de mercúrio do mundo, em 500 anos de história, foram extraídas cerca de 147.000 toneladas de mercúrio, correspondendo a mais de $13 \%$ da produção mundial.

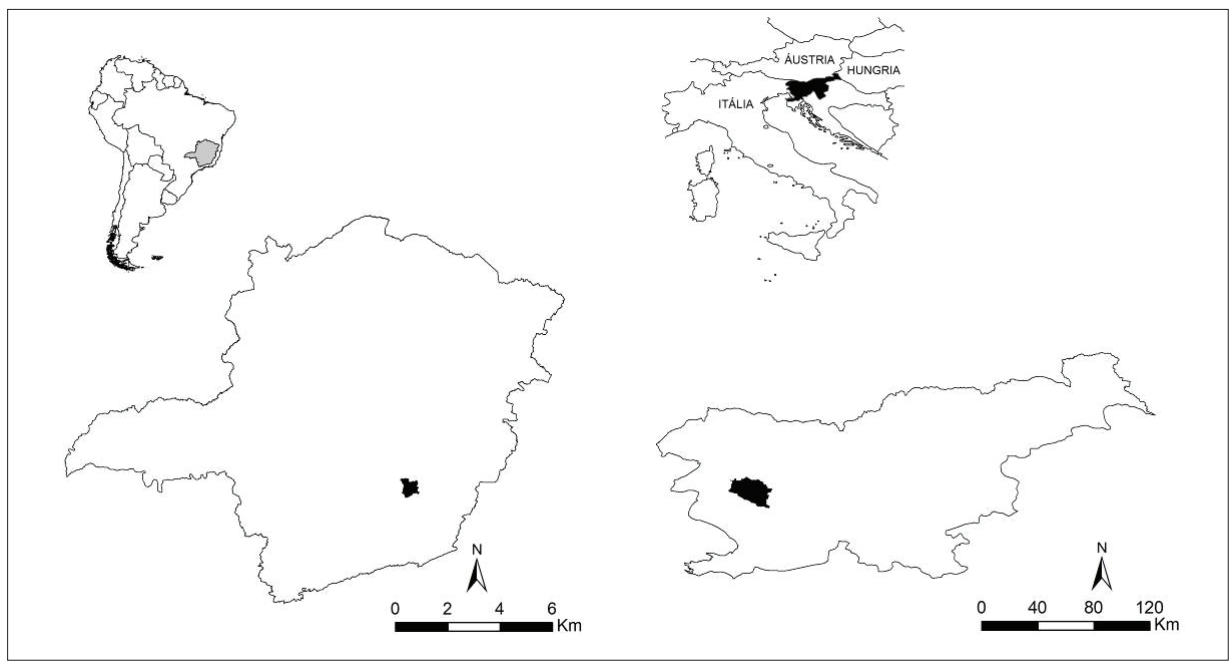

Figura 1. Mapas simplificados de localização dos municípios onde se localizam as minas apresentadas no trabalho em relação à região no mundo, país e estado.

\section{Breve histórico da mineração no contexto das minas estudadas}

Data do final do século XVII a descoberta do ouro na região de Vila Rica e Mariana pela bandeira comandada por Manoel Garcia Velho de Taubaté, que, percorrendo os cursos d'água da bacia do rio Doce, atingiu o ribeirão do Carmo, localizando ouro aluvionar em abundância. Durante alguns anos, depois das primeiras descobertas, as prospecções por bateia foram avaliando o ouro ao longo do Ribeirão do Carmo até que, segundo Cunha e Suszczynski (1978), em 1719, descobriram as jazidas primárias de Passagem (Ruchkys, 2007).

A mina da passagem compreende um aglomerado de antigas lavras, cujas concessões foram obtidas a partir de 1729 por uma série de mineiros, sendo compostas ao todo de quatro lavras: 1) Fundão, 2) Mineralógica, 3) Paredão e 4) Mata-Cavalo. Segundo Ferrand (1894) e Calógeras (1938), a lavra mais importante de Passagem, a Mineralógica, foi adquirida em 1784 por José Botelho Borges e, a partir da segunda metade do século XVII, o decréscimo dos teores de ouro e a falta de técnica para aprofundar a exploração levaram ao declínio das atividades de mineração. Com a vinda da família real portuguesa para o Brasil foi contratado o mineralogista e geólogo Wilhelm Ludwig von Eschwege que ao chegar ao Brasil, ficou encarregado de levantar a situação 
das minas de ouro em Minas Gerais, estudar formas de melhorar a produção e avaliar as possibilidades de implantar novas técnicas de mineração capazes de reabilitar a falida indústria minerária do País.

Em 1819, Eschwege tornou-se proprietário da mina de Passagem e criou a primeira companhia mineradora do País, com o nome de Sociedade Mineralógica da Passagem. Instalou um engenho com nove pilões e moinhos para pedras, até então desconhecidos. Seu objetivo principal era que suas técnicas e maquinarias servissem de modelo para outras explorações demonstrando, assim, as vantagens da utilização de conhecimento científico para a mineração. Eschwege ficou a frente da mina de Passagem até 1821 e, a partir daí a mina passou pelas mãos de vários proprietários até ser comprada em 1863, pela Companhia inglesa Anglo-Brazilian Gold Mining Company (Ruchkys, 2007). Em 1883, a mina foi vendida à companhia Ouro Preto Gold Mines of Brasil que, de acordo com Duarte (1991), operou com sucesso até 1927 quando vendeu a propriedade com todas as instalações à Companhia Minas de Passagem.

Embora tenha passado por várias dificuldades, a companhia operou regularmente até 1954 quando as operações foram paralisadas, permanecendo assim até 1960. A paralisação ocorreu, principalmente, devido à conjuntura econômica do Brasil na época e à baixa cotação do ouro. Na década de 60 foram feitas várias tentativas de reabertura da mina, no entanto, em 1967, a mina foi novamente paralisada e permaneceu nesta situação até 1973 quando foi vendida ao Grupo da Companhia Anglo Brasileira de Construções. O grupo não obteve sucesso nas então desordenadas tentativas de desenvolver o empreendimento e, em 1976, o controle acionário foi transferido ao médico Dr. Walter Rodrigues, que também não conseguiu dar continuidade à exploração subterrânea (Ruchkys, 2007). Segundo Meyer (2003), a mina foi aberta à visitação pública em 1985 e passou a ser a primeira mina de ouro mecanizada aberta ao público no mundo.

A história da mineração em Idrija é bem mais antiga quando comparada a de Passagem, misturando-se à longa história do "Velho Mundo". Enquanto a última tem início no final do século XVII, os depósitos de mercúrio em Idrija foram descobertos casualmente em 1490 quando gotas de mercúrio foram encontradas nos xistos carboníferos, bem no centro da cidade, local onde hoje se encontra a Igreja da Santa Trindade. Em 22 de junho de 1580 um rico minério de cinábrio foi encontrado nas camadas triássicas Skonca. Com esse achado, tivera início centenas de anos de mineração próspera e em 1575, a administração de Viena (Áustria) passou a controlar a gestão da mina. Com toda a estrutura construída até o século XVII, a mina tornou-se tecnicamente a melhor dentro dos limites do Império Austríaco. Sua fama aumentou no século XVIII e durou até o início da Primeira Guerra Mundial, em 1914. Nas últimas décadas sob administração austríaca, diversos equipamentos de mineração e outros maquinários foram testados. A modernização da mina continuou após 1956 e durou até a interrupção dos trabalhos de mineração em 1977, quando o mercúrio se tornou pouco interessante economicamente, principalmente em função do crescimento da consciência ecológica. Conforme Režun et al. (2009), os trabalhos de fechamento parcial iniciaram-se em 1988, embora os depósitos de minério ainda não tivessem sido totalmente explotados, e finalizaram em fins de 
2009. Vários motivos influenciaram o abandono do processo de escavação e extração de mercúrio em Idrija. Um deles foi o início de uma intensa campanha internacional contra o uso do mercúrio, cujos efeitos nocivos foram amplamente estudados e divulgados por vários campos da ciência. Outro motivo foi o preço muito baixo do metal no mercado interno e externo. Vários anos se passaram antes que a administração estatal aprovasse e adotasse o plano de encerramento gradual da mina.

Para tanto, ênfase foi dada sobre os efeitos em longo prazo da mina em relação à subsidência ou afundamentos da superfície. Assim sendo, buscou-se destacar os riscos para a cidade de Idrija que está localizada acima da mina e suas instalações. Foram realizados estudos relacionados à instabilidade potencial das encostas naturais e artificiais na superfície e destaque também foi dado para a poluição ambiental pelo mercúrio na própria cidade e a jusante ao longo dos rios Idrijca e Soča, até o Golfo de Trieste, na Itália.

Režun et al. (2009) destacam que o fechamento da mina de mercúrio de Idrija foi acompanhado de observações e medições destinadas ao monitoramento dos seus efeitos, bem como por medições e estudos no âmbito do monitoramento ambiental da poluição pelo mercúrio. Atualmente destaca-se que os resultados das pesquisas indicam que o conceito de encerramento da mina foi bem sucedido, pois os componentes individuais do programa de fechamento foram melhorados e ajustados de acordo com os resultados reais das obras. Tais resultados serão utilizados como diretrizes para o planejamento futuro do monitoramento que deve, entre outros aspectos, garantir a segurança da cidade e seus arredores, bem como a reabilitação do ambiente.

Em 22 de junho de 1994, após trabalhos de restauração, a parte mais antiga da mina conhecida como Anthony's Main Road foi aberta ao público e a mina passou a ser conhecida como a primeira da Eslovênia a ser aberta ao turismo.

\section{Geologia das minas da Passagem e de Idrija}

Sobre os depósitos de ouro da região do Quadrilátero Ferrífero, RibeiroRodrigues (1998) propõe uma classificação em três categorias diferentes tendo como base a idade e os tipos de rochas hospedeiras, a saber: 1) aqueles hospedados em rochas arqueanas do Supergrupo Rio das Velhas; 2) os hospedados em rochas metassedimentares paleoproterozóicas do Supergrupo Minas; e 3) aqueles hospedados em coberturas aluvionares e lateríticas.

Os corpos de minério de Passagem estão inseridos no Supergrupo Minas, na zona de contato entre a Formação Cauê, no topo, e o Grupo Caraça (Formação Moeda e Batatal) ou Grupo Nova Lima (Supergrupo Rio das Velhas). A Mina de Passagem encontra-se estruturada no Anticlinal de Mariana, localizando-se no flanco sul desta estrutura.

Segundo Ruchkys (2007), as primeiras descrições geológicas sobre as jazidas e ocorrências de ouro na região da Mina de Passagem se devem a Eschwege, cujas 
observações foram feitas no período de 1811 a 1821 e publicadas no primeiro volume do Pluto Brasilienses de 1833. Ladeira (1988) caracteriza o minério como aparentemente incomum, constituindo-se de um turmalinito, chamado pelos mineiros historicamente de carvoeira (nome já utilizado por Eschwege. Contem arsenopirita (principal mineral hospedeiro do ouro), quartzo leitoso e dolomito que, intimamente associados, constituem a rocha portadora das mineralizações. Vial (1988) identifica, também, um segundo tipo de minério associado a anfibólio-xisto-pirrotitíco (Ruchkys, 2007).

Os sulfetos perfazem até $15 \%$ do volume dos veios, sendo representados principalmente por arsenopirita. Pirrotita, pirita, calcopirita, galena, bertierita $\left(\mathrm{FeSb}_{2} \mathrm{~S}_{4}\right)$, lolingita $\left(\mathrm{FeAs}_{2}\right)$ e ingodita $\left(\mathrm{Bi}_{2} \mathrm{TeS}\right)$ ocorrem como traços (Vial, 1988). Guimarães e Coelho (1944) citados por Pereira e Santos (1984) descrevem ocorrência de scheelita $\left(\mathrm{CaWO}_{4}\right)$ e estibnita $\left(\mathrm{Sb}_{2} \mathrm{~S}_{3}\right)$ no minério aurífero de Passagem de Mariana. O ouro ocorre principalmente nos interstícios como inclusões e/ou em vênulas nos sulfetos e pode conter até 30\% de Ag conforme ressaltam Ribeiro-Kwitko e Oliveira (2004).

Em Idrija, o depósito de minério se localiza abaixo do centro da cidade e se estende por 1.500 metros na direção N-W e S-E, com 450 metros de profundidade e 400 a 600 metros de largura. A mina possui 15 níveis que alcançam 382 metros de profundidade a 36 metros abaixo do nível do mar. A estrutura do depósito é extremamente complexa e é o resultado de longo período de sedimentação e ocorrências tectônicas durante o Triássico e o Terciário. Os eventos ocorridos durante a formação dos depósitos Triássico e a transformação da estrutura anterior até seu estado atual são pouco comuns e atraem a atenção mundial por sua raridade e complexidade que foram foram preservadas, principalmente, nos depósitos de minério e no entorno da cidade de Idrija (Mlakar \& Drovenik, 1971; Bajželj \& Likar, 1991; Likar et al., 2006).

O depósito mineral de Idrija é composto por rochas Carboníferas, Permianas e Triássicas enriquecidas com cinábrio ( $\mathrm{HgS})$. O minério aparece em duas formas: 70\% como cinábrio $(\mathrm{HgS})$ e $30 \%$ como mercúrio nativo $(\mathrm{Hg})$ sendo o cinábrio, portanto, o depósito principal. Em toda área do depósito mineral, existem 158 corpos de vários tamanhos e formas sendo 141 de cinábrio e 17 deles com mercúrio nativo encontrado em xistos e siltitos carboníferos bem como em tufas com materiais piroclásticos e detríticos, do Ladiniano. A qualidade da mineralização é extremamente diversificada, variando de minérios ricos com até $78 \%$ de mercúrio a depósitos pobres com uma média de $0,20 \%$ do mineral, encontrados pouco antes do fechamento da mina.

\section{Gerenciamento da visitação e manutenção das minas}

A gestão da mina da Passagem é feita pela empresa privada OPM Empreendimentos Ltda. (http://www.minasdapassagem.com.br/) que é responsável por todas as atividades ligadas a visitação. A mina integra o Circuito Turístico do Ouro, assim denominado pela Secretaria de Estado de Turismo de Minas Gerais que apoia um programa de desenvolvimento do turismo no Estado baseado em circuitos que unem municípios com uma mesma vocação turística. 
Embora a mina seja um dos pontos turísticos de grande interesse no contexto do Circuito do Ouro, não existe capital do governo envolvido no sistema de gestão que inclui, além da visitação propriamente dita, a manutenção do espaço musealizado e de suas instalações. Em 2012 foi criado um sistema de gestão integrada do Circuito do Ouro que propôs o fortalecimento da cadeia hoteleira regional, a promoção e o marketing dos destinos na captação de eventos nacionais e internacionais. Além disso, com a proposta buscou-se o fortalecimento da gestão turística nos municípios, dos empresários e da cadeia produtiva do turismo regional com vistas a uma melhor qualidade no atendimento.

A falta de um programa de gestão de longo prazo prejudica a visitação da mina que passou por poucas modificações desde que foi aberta ao público. Seria importante um programa continuo de gestão que envolvesse a continuidade da seleção e preparação de novas galerias para visitação, bem como a concepção de materiais expositivos in situ incluindo painéis, bonecos de dimensões humanas que sejam posicionados estrategicamente para demonstrar a vida na mina. Além disso, a existência de maquinários que resgatassem e valorizassem os processos de extração mineral, a exemplo do que ocorre em Idrija e em outras minas abertas a visitação no mundo, ajudaria na projeção e incremento do turismo na região.

Na Eslovênia, em Idrija, o Governo transformou em 1995 a empresa Idrija Mercury Mine em uma empresa corresponsável pelo fechamento gradual da mina de mercúrio sob o nome de Idrija Mercury Mine, cujo único fundador e proprietário é a República da Eslovênia. Já em 2004, a Assembleia Nacional Eslovena aprovou uma emenda à Lei sobre a prevenção dos efeitos das atividades de mineração na Idrija Mercury Mine, cujo objetivo era expandir a lei para incluir a recuperação das perdas da mineração e eliminar os efeitos das atividades na saúde dos antigos mineiros. A Lei também prevê que, após a conclusão das obras de fechamento, as atividades da mina deveriam ser alteradas para a manutenção e monitoramento da seção não inundada e manutenção do museu da mina. Destaca-se que a manutenção da mina após obras de desligamento continua a ser uma tarefa permanente no futuro.

Em 2007, o governo esloveno aprovou e adotou um programa de manutenção da parte não inundada da mina e o monitoramento após a conclusão das obras de fechamento em um Projeto de encerramento gradual no período de 2008-2012. O programa foi pensado para possuir uma análise das atividades de encerramento realizadas, as atividades de manutenção planejadas para as entradas da mina, a demolição e mudança do uso da infraestrutura de superfície, a manutenção da mina após a conclusão das obras de fechamento, seu monitoramento após a conclusão das obras de fechamento, a criação de um centro de informação e pesquisa sobre o mercúrio, um programa de reestruturação da empresa e uma avaliação dos danos causados pela mineração. Todas as atividades previstas no programa são de responsabilidade da empresa pública, Idrija Mercury Mine. 


\section{Estratégias de utilização do patrimônio geológico e mineiro}

A mina da Passagem está aberta a visitação pública e tem uma estrutura que inclui restaurante, loja de artesanato e um museu com peças do ciclo do ouro em Minas Gerais. A visita é guiada e utiliza estudantes da comunidade local. Tem início com a descida na mina por meio de um trolley acionado por um guincho elétrico e que acessa o subterrâneo pelo plano inclinado. As galerias subterrâneas alcançam 120 metros de profundidade. A visita é rápida, durando cerca de 30 minutos, e somente uma pequena parte da mina está preparada para visitação com sistema de iluminação. Não existe nenhum recobrimento no piso, nem escadas ou outras instalações que facilitem o deslocamento. Dentro da mina a temperatura é estável e varia entre 17 e $20^{\circ} \mathrm{C}$.

Nas galerias o visitante recebe informações a respeito da história da mina, bem como dos antigos métodos de exploração. Além disso, informações básicas sobre a rocha hospedeira do minério são passadas aos visitantes. A exploração de temas importantes para o entendimento da prática de lavra subterrânea é feita de forma superficial. Sabe-se que, como salienta Meyer (2003), em Passagem foram criados planos inclinados pois era usado um sistema de via férrea para transferência de material dos depósitos para os planos inclinados e o minério desses para a usina de tratamento. Era empregado o método de lavra por câmaras e pilares, deixando-se pilares em intervalos variáveis, porém compatíveis com a sustentação do teto. A construção desses pilares artificiais era feita pela superposição de pedra seca, de forma artesanal, o que a torna quase uma obra de arte.

Guimarães et al. (2009) chamam a atenção para uma imagem de Santa Bárbara, padroeira dos mineiros e que foi colocada no interior da mina. O pequeno altar é ponto de parada durante a visitação e em homenagem à Santa, ao lado da imagem, existe uma mesa para depósito de oferendas. Materiais como flores, bijuterias, vidros de perfumes, velas, batons, entre outros, podem ser encontrados.

No interior da mina a visita termina com uma visão do lago natural de águas cristalinas e ótima visibilidade. O lago foi formado em decorrência da inundação pelo lençol freático de túneis e galerias após o encerramento das atividades de mineração. A equipe da antiga Divegold adquiriu a concessão para a exploração do mergulho na Mina da Passagem em julho de 1999, quando passaram a atuar intensamente para estruturála para o mergulho técnico com o cabeamento de algumas galerias. No fundo do lago é possível encontrar resquícios históricos tais como picaretas e latrinas, dentre outros diversos artefatos. São oferecidos mergulhos em grupos ou acompanhados apenas de um instrutor.

Ao sair da mina o visitante pode ter a experiência de batear o ouro em um tanque colocado ao lado da entrada. Além disso, o turista pode visitar o museu e a loja de artesanatos que comercializa exemplares de minerais e souvenirs produzidos pela comunidade local, principalmente com utilização de pedra sabão. O restaurante bem ao lado da boca da mina tem pratos e doces típicos de Minas Gerais. Na figura 2 são apresentadas várias estratégias de fruição do patrimônio geológico e mineiro adotados na visita à Mina de Passagem. 

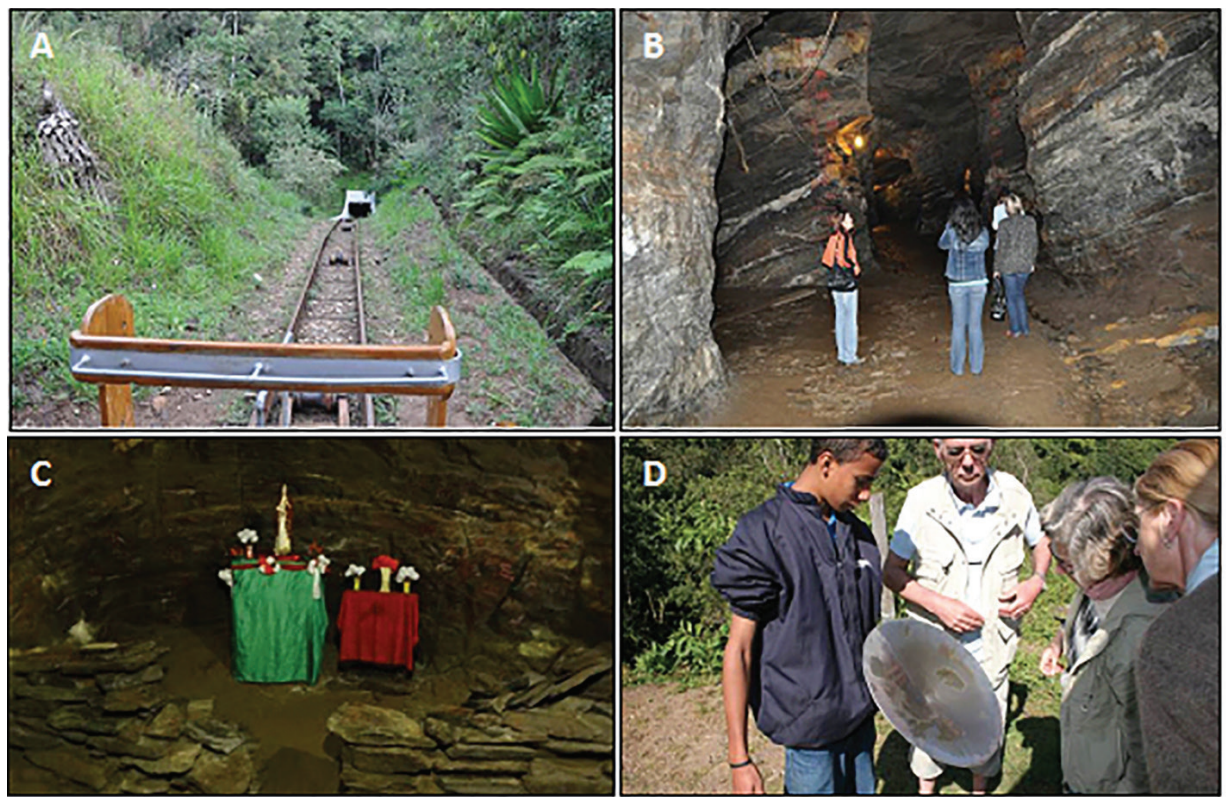

Figura 2. Aspectos da mina de Passagem de Mariana e estratégias adotadas para fruição do patrimônio: (a) Entrada da mina de Passagem acessada por meio de um trolley; (b) Pilares artificiais feitos pela superposição de pedra seca; (c) Imagem de Santa Bárbara com oferendas colocadas pelos visitantes; (d) Visitantes bateando o ouro na saída da visita à mina (Fonte: a,b,d-acervo dos autores; c- Márcio Mattos).

A parte mais antiga da mina de Idrija, conhecida como Anthony's Main Road, foi aberta a visitação em 1994, após trabalhos de restauração. A mina tem uma das entradas (Anthony's shaft) mais bem preservadas de todo o mundo que foi escavada em apenas uma década após a descoberta de mercúrio no século XV. Por quase meio milênio, os mineiros desceram diariamente pelos exatos 300 metros da abertura vertical para o subterrâneo. Em meados do século XVIII, a Capela da Santíssima Trindade foi construída pelos mineiros no final da entrada e apresenta duas estátuas de seus patronos, Santo Acácio e Santa Barbara.

A mina é visitada anualmente por cerca de 25.000 pessoas, dentre grupos de alunos de escolas locais e turistas nacionais e estrangeiros. A visita tem início com a apresentação de um vídeo que conta a história da mina e dos mineiros que trabalharam nela. Após a exposição do vídeo, os visitantes se vestem como mineiros e colocam o capacete de segurança. Os túneis e galerias estão preparados com apresentações pitorescas que recriam e demonstram o trabalho duro feito pelos mineiros ao longo dos anos, permitindo ao visitante ter uma ideia geral sobre os 500 anos de atividade de mineração. Cada nível é dedicado a temas diferentes como o carregamento e transporte 
do minério, as escavações mecânicas, perfurações e explosões; e a exposição das gotas de mercúrio nativo in situ.

Além da proposta de visitação turística local, outra importante atividade é a preparação de material de promoção, apresentações e organização de workshops. Por muitos anos, seminários da área das ciências naturais foram organizados como uma das atividades relacionadas à mineração para professores de escolas de ensino fundamental e médio como parte da educação profissional do Ministério do Esporte e da Educação.

Ao organizar parte da mina para visitas turísticas, os gestores se preocuparam em reproduzir para os visitantes as condições de trabalho e o próprio trabalho na mina, bem como exibir o mercúrio e os minérios encontrados na região. Há vários anos a equipe tem dedicado atenção especial a grupos de especialistas como estudantes de engenharia de minas, geologia e ciências afins, o que já ocorria enquanto a minha estava ativa. Eram comuns as visitas de alunos da Universidade de Ljubljana, bem como de outras universidades europeias como as de Munique, Heidelberg, Karlsruhe, Viena, Leoben, Innsbruck, Trieste, Paris e Liege. Entre as atividades destaca-se a possibilidade de aulas de campo dedicadas ao mapeamento geológico subterrâneo. O programa inclui trabalho de campo teórico e prático, o que raramente é oferecido aos estudantes em outros lugares. Na Figura 3 são apresentadas várias estratégias de utilização do patrimônio geológico e mineiro adotados na visita à Mina de Idrija.
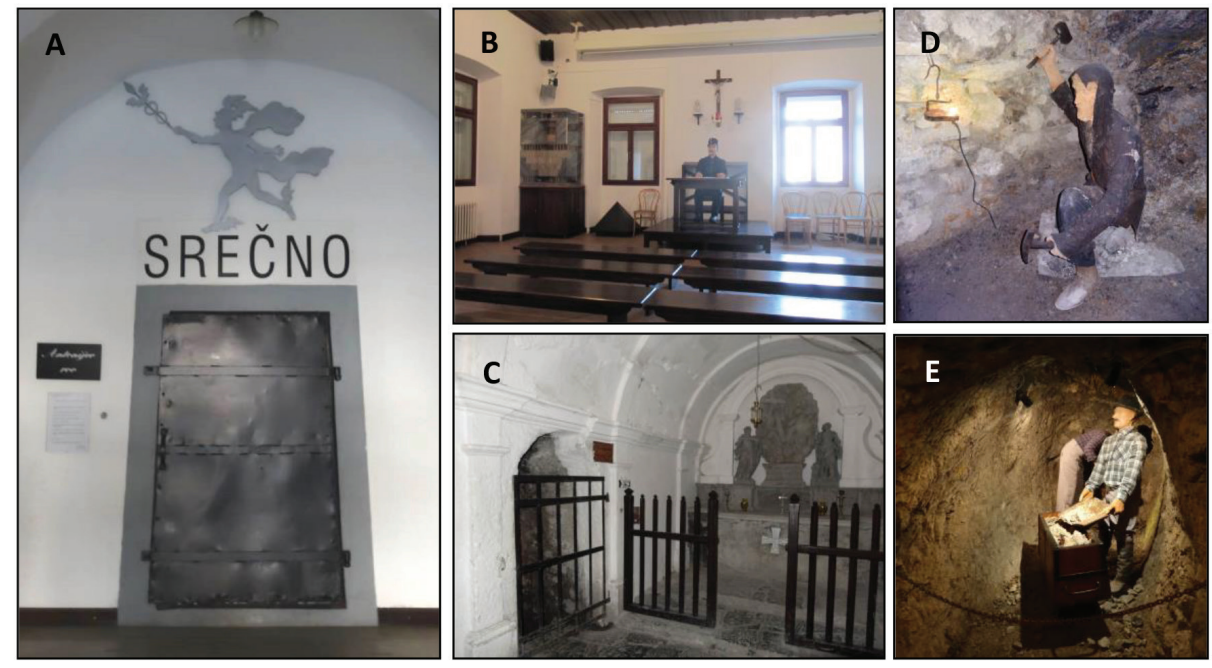

Figura 3. Aspectos da mina de mercúrio de Idrija e as estratégias adotadas para fruição do patrimônio: (a) Entrada da mina de Idrija com a palavra "Sorte" escrito em esloveno; (b) Local onde é apresentado o vídeo que conta a história da mina; C) Capela da Santíssima Trindade com o local original de entrada dos mineiros. Hoje é por onde os turistas saem após o final da visitação; (d) Representação de um trabalhador e sua condição de trabalho durante a Idade Média; e) Manequim em escala 1:1 com roupas e condições de trabalho da década de 60/70.

Fonte: acervo dos autores. 


\section{Considerações finais}

O patrimônio geológico e mineiro, nas mais diversas fases da história da mineração, pode servir como motor do desenvolvimento local nas regiões mineiras. Por esse motivo, faz-se necessário seu inventariamento, conservação e valorização. Neste sentido, é importante pensar o uso futuro e tomar as medidas cabíveis durante o processo de fechamento de minas para que áreas com importante patrimônio geológico e mineiro sejam protegidas. Deve-se pensar no uso turístico e educativo de uma mina antes de seu fechamento para que se possa garantir que este uso ocorra de forma a aproveitar o máximo possível o potencial educativo e didático da mina, conforme o exemplo de Idrija, na Eslovênia).

Carvajal e González (2003) salientam que é muito mais interessante fazer esforços para utilização turística de minas exauridas do que simplesmente fechá-las e restaurar a topografia e vegetação da parte a céu aberto. As galerias e túneis de uma mina, escavados por muitos anos ou séculos, permitem a exposição de afloramentos de rochas e minerais contendo vestígios arqueológicos valiosos que servem para conhecer um pouco mais sobre a nossa história, valorizando depósitos minerais e operações de mineração, cujos produtos tiveram grande influência sobre o desenvolvimento dos países onde se inserem.

Uma alternativa é a criação de parques temáticos mineiros que valorizem um tipo de atividade que foi e é muito importante como fornecedora de matérias-primas necessária para a qualidade de vida das populações. Muitas minas, com as de Passagem e Idrija, são representativas das identidades coletivas do patrimônio territorial.

A valorização do patrimônio geológico e mineiro, além de contribuir com a divulgação pública sobre a importância dos recursos minerais para a sociedade, pode ser uma alternativa econômica, ambiental e social após o encerramento das minas ativas que prolonga, portanto, seu tempo de vida. Esta é, sem dúvida, uma estratégia interessante para mudar a imagem negativa da mineração levando as pessoas a entenderem seu verdadeiro significado e importância na nossa sociedade.

Desta forma, minas desativadas podem passar da condição de passivos ambientais para locais de utilidade pública, valorizando o patrimônio geológico e mineiro e assegurando que o seu valor seja legitimado integrando-o à comunidade local. O fomento das atividades turísticas em minas preparadas para visitação com proposta museológica adequada pode, inclusive, levar a um aumento do fluxo de visitantes em localidades que antes viviam da atividade mineraria atualmente exaurida. Isso pode desencadear uma série de impactos positivos ligados a questões sociais, econômicas, ambientais e educacionais.

No panorama brasileiro ainda há muito o que se fazer para valorização efetiva do patrimônio mineiro: existe, no país, um abandono de muitas minas inativas que acabam se degradando com o tempo. Além disso, é frequente a descaracterização e dilapidação do patrimônio mineiro e observa-se a própria falta de interesse das empresas mineradoras em destinar suas minas inativas para atividades turísticas e educativas. Seria interessante 
que minas consideradas historicamente importantes tivessem um plano de fechamento associado a propostas proteção e de adequação para uso turístico e educativo.

Espera-se que a experiência de aproveitamento de antigas minas para este fim, como observado nos casos de Passagem e Idrija, possa estimular iniciativas semelhantes no Quadrilátero Ferrífero, onde existem muitas minas historicamente importantes, tanto a céu aberto como subterrâneas, muitas delas, desativadas. Citam-se aqui os casos das minas de Morro Velho (Nova Lima), Congo Soco (Barão de Cocais), Honório Bicalho (Nova Lima) e Cata Branca (Itabirito). Talvez, a musealização de todas estas minas poderia proporcionar uma valorização da própria atividade de mineração em um circuito de visitação pela história das minas em Minas Gerais.

\section{Referências}

BRILHA, J. Patrimônio geológico e geoconservação: a conservação da natureza na sua vertente geológica. Braga: Palimage, 2005. 190 p.

CUNHA, C. J.; SUSZCZYNSKI, C.A.. Cia. Minas da Passagem. Mariana: CMP, 1978, v.3, 31p.

BAJŽELJ, U.; LIKAR, J. Analysis of the stress-deformation state in the wider area of stopes at the Idrija Mine. Bolletino della Associazione Mineraria Subalpina, v.28, n.4, p. 699-712, 1991.

CARCAVILLA, U. et al.. Geodiversidad y patrimonio geológico. 2 ed. Madrid: Instituto Geológico y Minero de España, 2012, 21p. Disponível em: <http://www.igme.es/internet/ patrimonio/novedades/Folleto_Patrimonio2edicion.pdf>. Acesso em 30 set. 2014.

CARVAJAL, D. J.; GONZÁLEZ, A.. La contribución del patrimonio geológico y minero al desarrollo sostenible. In: ROBERTO C.; VILLAS-BÔAS, R.C.; GONZÁLEZ, A. Patrimonio geológico y minero en el contexto del cierre de minas. Rio de Janeiro: CNPq/ CYTED, 2003, p.27-50.

CALÓGERAS, J.P. As minas do Brasil e sua legislação (geologia econômica do Brasil). São Paulo: Cia. Editora Nacional, 1938, Tomo 3, p.104-412.

CUNHA, C. J.; SUSZCZYNSKI, C. A. Cia. Minas da Passagem. Mariana: CMP, 1978, v.3, 31p.

DERBY, O. On the mineralization of the gold-bearing lode of Passagem, Minas Gerais, Brazil. American Jornal Sciences, n. 4, p. 185-190, 1911.

DUARTE, B. P. Contribuição ao estudo da geologia do corpo de minério fundão do depósito aurífero de Passagem, Mariana, MG. 1991. 175f. Dissertação (Mestrado)Universidade Federal do Rio de Janeiro, Rio de Janeiro, 1991.

ESCHWEGE, W. L. v. Pluto brasiliensis. Berlin: G. Reimer, 1833, 622p. Tradução de Domício de Figueiredo Murta. Belo Horizonte/São Paulo: Itatiaia/Ed. USP, 2 vol., 1976.

CALÓGERAS, J. P. As minas do Brasil e sua legislação (geologia econômica do Brasil). São Paulo: Cia. Editora Nacional, 1938, Tomo 3, p.104-412. 
FERRAND, P. M. O ouro em Minas Gerais. 1894, 366p. Tradução de Júlio Castanõn Guimarães, Notas João Henrique Grossi, Friederich E. Renger, Estudos Críticos João Henrique Grossi (et al). Belo Horizonte: Fundação João Pinheiro (Mineiriana), 1998.

FLEISCHER, R.; ROUTHIER, P.The “consanguineous" origin of a tourmaline-bearing gold deposit: Passagem de Mariana (Brazil). Economic Geology, n. 68, p.11-22, 1973.

GUIMARÃES, D. Princípios de metalogênese e geologia econômica do Brasil. Boletim do Serv. Geol. Min. do Brasil, n.121, 625p, 1965.

GUIMARÃES, R. L. et al. O geoturismo em espaços sagrados de Minas Gerais. EspeleoTema, v. 20, n. 1/2, p. 49-58, 2009. Disponível em: <http://www.sbe.com.br/espeleotema/espeleo-tema_v20_n1-2_049-058.pdf.>. Acesso em: 16 set. 2014.

LADEIRA, E. A. Metalogenia dos depósitos de ouro do Quadrilátero Ferrífero, Minas Gerais Brasil. In: SCHOBBENHAUS, C.; COELHO, C. E. S. (Eds.). Principais depósitos minerais do Brasil. Brasília: Edições do DNPM/CVRD, 1988, v.3, p. 301-375.

LIKAR, J.; CIGALE, M.; REŽUN, B. Long-term deformation processes in the wider area oft he closed Idrija Mercury Mine. RMZ - Materials and Geoevironment, v.53, n.1, p.103-120, 2006.

MARTÍNEZ, G. de A.; ALBUQUERQUE, S. C. de (Eds). Patrimonio geológico y minero en el contexto del cierre de minas. Rio de Janeiro: CNPq/CYTED, 2003, 260p.

MLAKAR, I.; DROVENIK, M. Strukturne in genetske posebnosti idrijskega rudišča. Geologija, n. 14, p. 67-126, 1971.

MEYER, E. O. Mina da Passagem: o extraordinário trabalho do homem em busca do ouro de 1719 até os dias de hoje. São Paulo: Espaço Editorial, 2003, 94 p.

ORTEGA VALCÁRCEL, J. El patrimonio territorial: el territorio como recursos cultural y económico. Ciudades, n.4, p. 33-48, 1998.

PEREIRA, R. M.; SANTOS, R. A. A ocorrência de scheelita estratiforme de Caeté, MG: base de uma nova interpretação metalogenética para os índices de W, Sb, Hg do Quadrilátero Ferrífero. Mineração e Metalurgia, n.450, p.38-43, 1984.

REŽUN, B.; PELJHAN, M.; KOVAČIČ, M. Idrija - Slovenian Treasure. In: NETO DE CARVALHO, C.; RODRIGUES, J. C. (Eds.). Geoturismo \& Desenvolvimento Local. Idanha-a-Nova: Edição própria, 2009, p.121-137.

RIART, O. P. La conservación del patrimonio geológico y minero. In: INSTITUTO GEOLÓGICO Y MINERO DE ESPAÑA. Ciento cincuenta años (1849-1999) estudio e investigación en Ciencias de la Tierra. Madrid: IGME, 2000, p. 73-101.

RIBEIRO-KWITKO, R. OLIVEIRA, I. G. O depósito aurífero de Antônio Pereira, Quadrilátero Ferrífero: condições p-t e natureza dos fluidos mineralizadores. Revista Brasileira de Geociências, v.34, n.1, p.117-126, 2004.

RIBEIRO-RODRIGUES, L. Gold mineralization in Archaean banded iron-formation of the Quadrilátero Ferrifero: The Cuibá mine, Minas Gerais, Brazil. 1998. 262f. Tese (Doutorado) - Universidade Técnica de Aachen (Alemanha), 1998. 
RUCHKYS, U. A. Patrimônio geológico e geoconservação no Quadrilátero Ferrifero, Minas Gerais: potencial para criação de um geoparque da UNESCO. 2007. 211f. Tese (Doutorado) - Instituto de Geociências da Universidade Federal de Minas Gerais, Belo Horizonte, 2007.

VIAL, D. S. Mina de ouro de Passagem, Mariana, Minas Gerais. In: SCHOBBENHAUS, C.; COELHO, C. E. S. (Ed.). Principais Depósitos Minerais do Brasil. Brasília: Edições do DNPM/CVRD, 1988, v.3, p. 421-430.

\section{ÚRSULA RUCHKYS}

Doutora em Geologia pela Universidade Federal de Minas Gerais, Mestre em Geografia pela PUC Minas e graduada em Geologia pela Universidade Federal de Minas Gerais. Atualmente é professora adjunta do Departamento de Cartografia e do Programa de Pós-Graduação em Análise e Modelagem de Sistemas Ambientais do Instituto de Geociências da Universidade Federal de Minas Gerais.

Av. Antônio Carlos, 6627 - Instituto de Geociências - Pampulha - 31270-901 Belo Horizonte, MG - Brasil.

E-mail: tularuchkys@yahoo.com.br

\section{Luiz Eduardo Panisset Travassos}

Doutor em Geografia pela PUC Minas, Doutor em Carstologia pela Universidade de Nova Gorica (Eslovênia), Mestre e Bacharel Licenciado em Geografia pela Pontifícia Universidade Católica de Minas Gerais. Atualmente é professor adjunto do Departamento de Geografia e do Programa de Pós-Graduação em Geografia da PUC Minas.

Av. Itaú, nr. 505 - Prédio Emaús - Dom Cabral - Belo Horizonte, MG - 30.535-

012

E-mail: luizepanisset@gmail.com

\section{BOJAN REŽUN}

Geólogo pela Universidade de Ljubljana, Eslovênia. Trabalhou na Mina de Mercúrio de Idrija até seu fechamento, vice-prefeito de Idrija e, atualmente, é Coordenador do Grupo de Especialistas do Geoparque de Idrija.

Geopark Idrija (Slovenia)

Center za idrijsko dediščino, Ulica IX. korpusa 17, 5280 Idrija

E-mail: bojan.rezun@gmail.com 